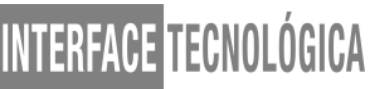

\section{ANÁLISE QUALI -QUANTITATIVA DA VEGETAÇÃO DA PRAÇA DR. WALDEMAR D'AMBRÓSIO, TAQUARITINGA-SP}

\section{QUALI-QUANTITATIVE ANALYSIS OF THE VEGETATION OF THE "PRAÇA DR. WALDEMAR D'AMBRÓSIO, TAQUARITINGA-SP}

\author{
Lucas Nunes Vicente-lukaum33@hotmail.com \\ Faculdade de Tecnologia (Fatec) - Taquaritinga - SP - Brasil \\ Marcela Midori Yada de Almeida - marcelayada@gmail.com \\ Faculdade de Tecnologia (Fatec) - Taquaritinga - SP - Brasil
}

DOI: 10.31510/infa.v17i2.946

Data de publicação: 18/12/2020

\begin{abstract}
RESUMO
Sabendo-se da importância em se analisar as praças e demais áreas verdes existentes no meio urbano, uma vez que isto direciona ações de manutenção e conservação destes espaços, este trabalho teve como objetivo analisar quali-quantitativamente a vegetação presente na Praça do Centenário, no município de Taquaritinga-SP. Foi realizado o levantamento da vegetação existente na praça, onde as espécies foram identificadas pelo nome popular e quantificadas e, em seguida, foram pesquisados: nome científico, família botânica e origem das espécies e tabulados o número de indivíduos arbóreos, o número total de espécies, o número de espécies por família e o número de indivíduos por família. Foram encontradas 21 espécies arbóreas e 10 arbustivas e herbáceas, distribuídas em 21 famílias botânicas, além de uma espécie de palmeira e 13 espécies de árvores não identificadas; 124 indivíduos, sendo 65 árvores e 59 palmeiras; deste montante, 14 indivíduos de 13 espécies de árvores e um indivíduo de palmeira, não foram identificados. A espécie com maior número de indivíduos foi a Syagrus romanzoffiana (jerivá), com 20 exemplares, representando 16,1\%, do total de indivíduos. A família Arecaceae foi a que apresentou maior número de espécies arbóreas (oito) e maior número de indivíduos (59), representando $22,9 \%$ de todas as espécies e $47,6 \%$ de todos indivíduos deste segmento, respectivamente. Considerando as espécies como um todo, 32,3\% são nativas do Brasil, e $67,7 \%$ são exóticas. Relacionado às espécies arbustivas e herbáceas, foram encontradas 10 espécies, distribuídas em nove famílias, sendo a Poaceae a única com duas espécies representantes.
\end{abstract}

Palavras-chave: Praças. Paisagem urbana. Urbanização urbana. Áreas verdes.

\begin{abstract}
Knowing the importance of analyzing the squares and other green areas existing in the urban environment, since this directs actions for the maintenance and conservation of these spaces, this work aimed to analyze qualitatively and quantitatively the vegetation present in Praça do
\end{abstract}


Centenário, in municipality of Taquaritinga-SP. The survey of the existing vegetation in the square was carried out, where the species were identified by the popular name and quantified and, afterwards, it were researched: scientific name, botanical family and origin of the species and tabulated the number of tree individuals, the total number of species, the number of species per family and the number of individuals per family. There were 21 tree species and 10 shrub and herbaceous, distributed in 21 botanical families, in addition to one specie of palm and 13 species of unidentified trees; 124 individuals, 65 trees and 59 palm trees; of this amount, 14 individuals from 13 species of trees and one individual from palm trees were not identified. The species with the largest number of individuals was Syagrus romanzoffiana (jerivá), with 20 specimens, representing $16.1 \%$, of the total of individuals. The Arecaceae family had the highest number of tree species (eight) and the largest number of individuals (59), representing $22.9 \%$ of all species and $47.6 \%$ of all individuals in this segment, respectively. Considering the species as a whole, $32.3 \%$ are native to Brazil, and $67.7 \%$ are exotic. Related to shrub and herbaceous species, it were found 10 species, distributed in nine families, with Poaceae being the only one with two representative species.

Keywords: Squares. Urban landscape. Urban afforestation. Green areas.

\section{INTRODUÇÃO}

O crescimento urbano acelerado e sem planejamento adequado ocorrido nas últimas décadas, associado à constante supressão da vegetação nativa e, consequente ausência das áreas verdes nos centros urbanos, têm gerado inúmeros efeitos negativos ao meio ambiente e aos seres humanos. É de consenso mundial a importância e a necessidade da presença de áreas verdes públicas nos ambientes urbanos, uma vez que estas trazem inúmeros benefícios sociais, culturais e ecológicos gerados pelo contato do homem com a natureza (ONU, 2016; RIGOLON, 2016). Dessa maneira, a recuperação e o planejamento de áreas vegetadas são fundamentais para o alcance de cidades mais saudáveis, seguras e, ainda, sustentáveis (MORERO, 2007; CHIESURA, 2004).

Dentre os diversos tipos de áreas verdes nas áreas urbanas, as praças se destacam devido à grande biodiversidade empregada em seus projetos paisagísticos e ornamentais (ROCHA et al., 2004; SILVA e ALMEIDA, 2016).

As praças são espaços livres, públicos, urbanos, de manifestação social, cultural e política, destinados ao lazer e ao convívio da população, cuja história está diretamente ligada à evolução histórica do paisagismo e dos costumes da época (PIVETTA; PAIVA; NERI, 2008). Desde o seu surgimento, a praça pública tem grande importância para as atividades de inter- 


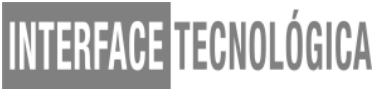

relação social, portanto, uma importante ferramenta histórica e cultural urbana e um reflexo direto do processo de urbanização (BENINI e MARTIN, 2010).

Conhecer a flora urbana faz parte de um programa de estudos que todo município deveria se preocupar desenvolver, visando a um plano de arborização que valorize tanto os aspectos ecológicos, quanto os paisagísticos das praças públicas (KRAMER e KRUPEK, 2012; VIEZZER et al., 2018). Entretanto, na maioria das cidades brasileiras, observa-se certa negligência referente à sua implantação dentro do planejamento e elaboração dos planos diretores municipais (MOREIRA et al., 2018).

Diante do exposto, sabendo-se da importância em se analisar as praças e demais áreas verdes existentes no meio urbano, uma vez que isto direciona ações de manutenção e conservação destes espaços, este trabalho teve como objetivo analisar quali-quantitativamente a vegetação presente na Praça do Centenário, no município de Taquaritinga-SP, visando sinalizar diante do poder público as necessidades de correções, adequações e melhorias do local.

\section{FUNDAMENTAÇÃO TEÓRICA}

\subsection{O ambiente urbano}

$\mathrm{O}$ crescimento da população mundial nas últimas décadas levou à um intenso e desenfreado processo de expansão urbana sem planejamentos adequados, ocasionando sérios problemas ambientais e, consequentemente, a perda da qualidade de vida da sociedade urbana (MORELLI, LIMA, SOUSA JUNIOR, 2012; COMUNE e SURIANI-AFFONSO, 2014).

Nas últimas décadas diversas pesquisas têm sido feitas visando à melhoria da qualidade de vida das populações e o desenvolvimento de cidades mais sustentáveis e mais verdes (RIGOLON, 2016).

\subsection{Importância das áreas verdes públicas}

Atualmente, as áreas verdes públicas é um assunto que vem sendo abordado constantemente. Por isso muitas pesquisas de diferentes áreas têm focado seus objetivos em mensurar e analisar estes locais, assim como compreender os efeitos gerados à população e ao ambiente onde se encontram (GARCIA, 2017). 


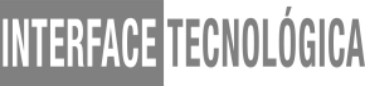

Áreas verdes públicas podem ser definidas como espaços verdes interconectados que conservam valores naturais de um ecossistema e que provêm benefícios às populações humanas (COUTTS e HAN, 2015). Estas áreas podem ser compostas por parques, florestas, praças, hortas comunitárias e outras formas de paisagens naturais públicas ou privadas (AMATOLOURENÇO, 2016), sendo indiscutível que todas essas categorias de verdes urbanos trazem diversos benefícios tanto para o ecossistema como para o homem (COSTA e FERREIRA, 2009; AMATO-LOURENÇO, 2016).

Entre os benefícios ecossistêmicos está a diminuição de temperaturas (OLIVEIRA; ANDRADE e VAZ, 2011), o que resulta em um decréscimo de ilhas de calor (SOLECKI et al., 2005); diminuição do escoamento superficial da água e da concentração de poluentes atmosféricos; redução de ruídos, de impactos de ventos e da incidência solar em pavimentos e construções (FANG e LING, 2005; NOWAK e DWYER, 2007), abrigo à fauna, equilíbrio do índice de umidade no ar, proteção das nascentes e dos mananciais, organização e composição de espaços no desenvolvimento das atividades humanas, valorização visual e ornamental do ambiente, recreação, diversificação da paisagem construída (LIMA et al., 1994; OLIVEIRA; SANTOS e PIRES, 1999; NUCCI, 2001; TOLEDO, MAZZEI e SANTOS, 2009). Estes efeitos contribuem ainda para a valorização de áreas para convívio social, valorização econômica das propriedades no mercado imobiliário (OLIVEIRA; SANTOS e PIRES, 1999; DONOVAN e BUTRY, 2010; HARNIK e CROMPTON, 2014) e para a formação de uma memória e do patrimônio cultural (OLIVEIRA; SANTOS e PIRES, 1999).

Entre os benefícios para o homem, as áreas verdes públicas podem aumentar a qualidade de vida por meio da geração de atividade recreativas, como a prática de esportes, brincar com as crianças ou passear com o cachorro, caminhar, tomar banhos de sol, conhecer outras pessoas, ou simplesmente experimentar e aproveitar a natureza (BYRNE e WOLCH, 2009). Estes locais agem também como espaços de encontros e interações sociais (MARTIN; WARREN; KINZIG, 2004). Além disso, o contato do homem com a natureza proporciona inúmeros benefícios a saúde humana (LAFORTEZZA, et al., 2009; VAN DEN BERG et al., 2010, 2016; CARRUS et al., 2015).

Embora a maioria das cidades apresentem praças públicas onde a população possa desfrutar de momentos de lazer e contato com a natureza, poucas têm esses espaços de forma organizada. Além disso, os recursos destinados às áreas verdes públicas sempre são escassos, levando ao abandono de parques e praças, que se transformam em áreas para crescimento 


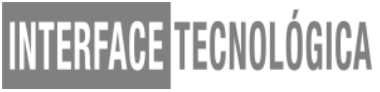

natural do mato e passam a ser um problema para a sociedade. Com isso, o cidadão, vê-se limitado entre o local de trabalho e sua residência, não podendo usufruir desses espaços de qualidade (RIGOLON, 2016).

Por isso, conhecer e monitorar a vegetação das áreas verdes urbanas para fins de planejamento é essencial para o direcionamento de ações futuras, como escolha de espécies adequadas, implantação e manejo adequado desses espaços (SOUZA, 2017). As diferentes espécies vegetais são exploradas, aleatoriamente, para diversos usos, levando-as quase a extinção pelo desconhecimento do manejo e usos adequados. Algumas espécies não identificadas, ou desconhecidas, podem constituir um impedimento para a exploração das reais potencialidades da vegetação nativa (LACERDA et al., 2011).

\section{MATERIAIS E MÉTODOS}

\subsection{Local do estudo}

O trabalho foi realizado na Praça Dr. Waldemar d'Ambrósio (Praça do Centenário), localizada no Centro da cidade de Taquaritinga. A praça possui área total de $7349 \mathrm{~m}^{2}$, ocupando um quarteirão inteiro.

O município de Taquaritinga está localizado no estado de São Paulo, nas coordenadas de latitude $21^{\circ} 24^{\prime} 44^{\prime \prime}$ Sul e longitude $48^{\circ} 29^{\prime}$ 53" Oeste, possuindo o território de 594,335 $\mathrm{km}^{2}$ e 579 metros de altitude. O município possui população estimada 57.177 habitantes, e densidade demográfica de 90,95 habitantes por $\mathrm{km}^{2}$ (IBGE, 2020).

Segundo a classificação de Köppen, o clima da cidade é tropical de altitude do tipo CWA, com verão quente e chuvoso e inverno moderado e seco. A temperatura média anual é de $24{ }^{\circ} \mathrm{C}$ e a precipitação média anual é de $1600 \mathrm{~mm}$.

O terreno apresenta relevo ondulado e o solo predominante é o Arenito de Bauru.

\subsection{Levantamento da vegetação}

Foi realizado o levantamento da vegetação existente na praça, onde as espécies presentes foram identificadas pelo nome popular e quantificadas por uma equipe de campo, composta por 3 pessoas, que utilizaram equipamentos como prancheta e lápis e aparelho fotográfico. 


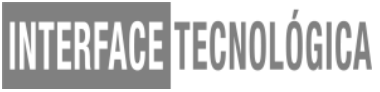

Como a maioria das espécies arbustivas e herbáceas é plantada em maciços, foi notado somente a presença da espécie não sendo contabilizado o número de indivíduos. A identificação das espécies foi realizada prioritariamente em campo no momento da coleta de dados, porém, quando esta identificação não foi possível, a vegetação foi fotografada e posteriormente identificada com base na literatura (LORENZI, 2013; LORENZI et al., 2003; 2018).

Baseado na literatura foram pesquisados: nome científico, família botânica e origem (nativa do Brasil ou exótica). Os seguintes dados foram tabulados: número de indivíduos arbóreos (árvores e palmeiras), número total de espécies, número de espécies por família e número de indivíduos por família.

\section{RESULTADOS E DISCUSSÃO}

Foram encontradas na Praça do Centenário, 21 espécies arbóreas (árvores e palmeiras) e 10 arbustivas e herbáceas, as quais estão distribuídas em 21 famílias botânicas (Tabelas 1 e 2). Além dessas, foram encontradas mais uma espécie de palmeira e 13 espécies de árvores não identificadas, totalizando assim, 35 espécies de árvores e palmeiras e 45 espécies vegetais presentes na praça.

Resultados semelhantes foram encontrados por Romani et al. (2012) na Praça XV de Novembro em Ribeirão Preto, SP e por Fernandes et al. (2018) na praça Rui Barbosa em São José do Rio Preto, SP, onde foram encontrados 34 e 28 espécies arbóreas nas praças amostradas, respectivamente.

Dentre as espécies arbóreas, foram contabilizados 124 indivíduos, sendo 65 árvores e 59 palmeiras; deste montante, 14 indivíduos de 13 espécies de árvores e um indivíduo de palmeira, não foram identificados (Tabela 1). A espécie que apresentou maior número de indivíduos foi a Syagrus romanzoffiana (jerivá), com 20 exemplares, seguida de perto pela Dypsis lutescens (areca-bambu), com 18 exemplares e, a Callistemon viminalis (escova-degarrafa-pendente), com 16 exemplares, representando 16,1\%, 14,5\% e 12,9\% do total de indivíduos, respectivamente (Tabela 1). Batista et al. (2013) e Messi Filho (2019) também verificaram alta representatividade de indivíduos de $S$. romanzoffiana, sendo a palmeira de maior ocorrência na praça D. Assis em Jaboticabal-SP, com 10 indivíduos e a segunda palmeira de maior ocorrência no Parque Municipal Antônio Augusto de Figueiredo, em Altinópolis-SP, com 25 indivíduos, respectivamente. 
Tabela 1. Espécies arbóreas (árvores e palmeiras) encontradas na Praça do Centenário, em Jaboticabal, SP; nome científico, nome popular, família botânica, número de indivíduos e origem.

\begin{tabular}{|c|c|c|c|c|}
\hline NOME CIENTÍFICO & NOME COMUM & FAMÍLIA & N. I. & ORIGEM \\
\hline \multirow{2}{*}{$\begin{array}{l}\text { Annona squamosa } \\
\text { Archontophoenix } \\
\text { cunninghamiana }\end{array}$} & Fruta do conde & Annonaceae & 1 & Exótica \\
\hline & Palmeira real & Arecaceae & 4 & Exótica \\
\hline Callistemon viminalis & Escova-de-garrafa-pendente & Myrtaceae & 16 & Exótica \\
\hline Caryota urens & Rabo-de-peixe & Arecaceae & 6 & Exótica \\
\hline Chamaecyparis lawsoniana & Cedro-branco & Cupressaceae & 1 & Exótica \\
\hline Dracena marginata & Dracena-de-madagascar & Asparagaceae & 1 & Exótica \\
\hline Dypsis decaryi & Palmeira triangular & Arecaceae & 1 & Exótica \\
\hline Dypsis lutescens & Areca-bambu & Arecaceae & 18 & Exótica \\
\hline Handroanthus heptaphyllus & Ipê rosa & Bignoniacea & 1 & Exótica \\
\hline Lagerstroemia indica & Resedá & Lythraceae & 6 & Exótica \\
\hline Licania tomentosa & Oiti & Chrysobalanaceae & 4 & Nativa \\
\hline Livistonia chinensis & Leque da china & Arecaceae & 6 & Exótica \\
\hline Magnolia champaca & Magnólia-amarela & Magnoliaceae & 1 & Exótica \\
\hline Mangifera indica & Mangueira & Anacardiaceae & 1 & Exótica \\
\hline Phoenix sp. & Palmeira fênix & Arecaceae & 3 & Exótica \\
\hline Podocarpus macrophyllus & Podocarpo & Podocarpaceae & 2 & Exótica \\
\hline Spathodea campanulata & Espatódea & Bignoniacea & 1 & Exótica \\
\hline Syagrus romanzoffiana & Jerivá & Arecaceae & 20 & Nativa \\
\hline Terminalia brasiliensis & Cerne amarelo & Combretaceae & 8 & Nativa \\
\hline Tibouchina granulosa & Quaresmeira & Melastomataceae & 5 & Nativa \\
\hline Tipuana tipu & Tipuana & Fabaceae & 3 & Nativa \\
\hline Não identificada 1 & Palmeira & Arecaceae & 1 & \\
\hline Não identificada 2 & Árvore & & 1 & \\
\hline Não identificada 3 & Árvore & & 1 & \\
\hline Não identificada 4 & Árvore & & 1 & \\
\hline Não identificada 5 & Árvore & & 1 & \\
\hline Não identificada 6 & Árvore & & 1 & \\
\hline Não identificada 7 & Árvore & & 1 & \\
\hline Não identificada 8 & Árvore & & 1 & \\
\hline Não identificada 9 & Árvore & & 1 & \\
\hline Não identificada 10 & Árvore & & 1 & \\
\hline Não identificada 11 & Árvore & & 1 & \\
\hline Não identificada 12 & Árvore & & 1 & \\
\hline Não identificada 13 & Árvore & & 1 & \\
\hline Não identificada 14 & Árvore & & 2 & \\
\hline $35 \mathrm{E}$ & CIES & 14 FAMÍLIAS & 124 & \\
\hline
\end{tabular}


A família Arecaceae apresentou maior número de espécies arbóreas (8) e maior número de indivíduos (59), representando $22,9 \%$ de todas as espécies e $47,6 \%$ de todos indivíduos deste segmento, respectivamente (Tabela 3).

Relacionado à origem, no seguimento de árvores e palmeiras (Tabela 1) há uma grande diferença, sendo encontradas apenas cinco espécies nativas, e 16 espécies exóticas, representando $23,8 \%$ e $76,2 \%$ do total de espécies encontradas, o que é esperado, uma vez que na maioria dos municípios brasileiros é bastante comum encontrar alta frequência de espécies exóticas. Já no segmento de arbustos e herbáceas (Tabela 2), houve um empate, sendo encontradas cinco espécies exóticas e cinco nativas.

Tabela 2. Espécies arbustivas e herbáceas encontradas na Praça do Centenário em Jaboticabal, SP. Nome científico, nome popular, família botânica, origem.

\begin{tabular}{lllc} 
NOME CIENTÍFICO & NOME COMUM & FAMÍLIA & ORIGEM \\
\hline Agave americana & Piteira azul & Asparagaceae & Exótica \\
Arachis repens & Grama amendoim & Fabaceae & Nativa \\
Bougainvillea spectabilis & Primavera & Nyctaginaceae & Nativa \\
Duranta erecta 'Gold Mound' & Pingo-de-ouro & Verbenaceae & Nativa \\
Ixora coccinea & Ixora & Rubiaceae & Exótica \\
Monstera adansonii variegata & Monstera & Araceae & Nativa \\
Paspalum notatum & Grama batatais & Poaceae & Nativa \\
Plumbago auriculata & Bela emília & Plumbaginaceae & Exótica \\
Rhododendron simsii & Azaleia & Ericaceae & Exótica \\
Zoysia japonica & Grama esmeralda & Poaceae & Exótica \\
\hline
\end{tabular}

Assim, considerando as espécies como um todo, 32,3\% são nativas do Brasil e 67,7\% são exóticas (Tabela 1), o que corrobora com a afirmação de Lorenzi et al. (2003), que comentam que as espécies exóticas representam cerca de $80 \%$ das espécies utilizadas no Brasil. Além de desvalorizar a flora nativa, especialmente a flora local, a introdução de espécies exóticas no ambiente urbano pode se tornar um problema preocupante (HOPPEN et al., 2014). Essa introdução é, na maioria das vezes, devido à um mau planejamento da arborização e, muitas vezes, ao desconhecimento dos problemas ambientais ocasionados por essas espécies e ao desconhecimento da legislação (SOUZA, 2017). 
Relacionado às espécies arbustivas e herbáceas, foram encontradas 10 espécies, distribuídas em nove famílias botânicas, sendo a Poaceae a única com duas espécies representantes (Tabela 3).

Tabela 3. Número total de espécies por família e número total de indivíduos por família da vegetação da Praça do Centenário em Jaboticabal, SP.

\begin{tabular}{lcc}
\multicolumn{1}{c}{ FAMÍLIA } & $\begin{array}{c}\text { TOTAL DE } \\
\text { ESPÉCIES/FAMÍLIA }\end{array}$ & $\begin{array}{c}\text { No }^{\mathbf{D}} \text { DE INDIVÍDUOS/ } \\
\text { FAMÍLIA }\end{array}$ \\
\hline Anacardiaceae & 1 & 1 \\
Annonaceae & 1 & 1 \\
Araceae & 1 & 0 \\
Arecaceae & 8 & 59 \\
Asparagaceae & 2 & 1 \\
Bignoniacea & 2 & 2 \\
Chrysobalanaceae & 1 & 4 \\
Combretaceae & 1 & 8 \\
Cupressaceae & 1 & 1 \\
Ericaceae & 1 & 0 \\
Fabaceae & 2 & 3 \\
Lythraceae & 1 & 6 \\
Magnoliaceae & 1 & 1 \\
Melastomataceae & 1 & 5 \\
Myrtaceae & 1 & 16 \\
Nyctaginaceae & 1 & 0 \\
Plumbaginaceae & 1 & 0 \\
Poaceae & 2 & 0 \\
Podocarpaceae & 1 & 2 \\
Rubiaceae & 1 & 0 \\
Verbenaceae & 1 & 0 \\
Não identificadas & 13 & 14 \\
21 FAMílIAS & $\mathbf{4 5}$ &
\end{tabular}

O gramado da praça é formado por uma mistura de Paspalum notatum (grama-batatais) e Zoysia japônica (grama-esmeralda). Provavelmente, foi plantada a grama-esmeralda aonde já existia a batatais, no entanto, observa-se o domínio de grama-batatais sobre grama-esmeralda, uma vez que, a grama-batatais ocorre naturalmente na região e mostra ser bastante agressiva e 


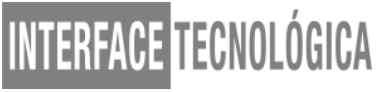

resistente, principalmente por apresentar rizomas e estolões. Segundo Lorenzi e Souza (2008), no Brasil, a maioria dos gramados em áreas urbanas era formada com esta espécie, entretanto, atualmente seu uso não é indicado por se tratar de produto de extrativismo.

\section{CONCLUSÃO}

Foram encontradas na Praça do Centenário, 21 espécies arbóreas (árvores e palmeiras) e 10 arbustivas e herbáceas, distribuídas em 21 famílias botânicas, além de uma espécie de palmeira e 13 espécies de árvores não identificadas. Dentre as espécies arbóreas, foram contabilizados 124 indivíduos, sendo 65 árvores e 59 palmeiras; deste montante, 14 indivíduos de 13 espécies de árvores e um indivíduo de palmeira, não foram identificados.

A espécie que apresentou maior número de indivíduos foi a Syagrus romanzoffiana (jerivá), com 20 exemplares, representando 16,1\%, do total de indivíduos. A família Arecaceae foi a que apresentou maior número de espécies arbóreas (oito) e maior número de indivíduos (59), representando $22,9 \%$ de todas as espécies e $47,6 \%$ de todos indivíduos deste segmento, respectivamente.

Considerando as espécies como um todo, 32,3\% são nativas do Brasil, e 67,7\% são exóticas. Relacionado às espécies arbustivas e herbáceas, foram encontradas 10 espécies, distribuídas em nove famílias, sendo a Poaceae a única com duas espécies representantes.

\section{REFERÊNCIAS}

AMATO-LOURENÇO, L.F.; MOREIRA, T.C.L.; ARANTES, B.L.; SILVA FILHO, D.F.; MAUAD, T. Metrópoles, cobertura vegetal, áreas verdes e saúde. Estudos Avançados, v.30, n.86, 2016.

BATISTA, G.S.; BORELLA, H.D.; GIMENES, R.; ROMANI, G.N.; PIVETTA, K.F.L. Análise qualiquantitativa da vegetação e dos elementos arquitetônicos da praça Dom Assis, Jaboticabal, São Paulo. Revista Brasileira de Horticultura Ornamental, v.19, n.1, p.7- 18, 2013.

BENINI, S. M., MARTIN, E. S. Decifrando as áreas verdes públicas. Revista Formação (Online), v.2, n.17, 2011.

BYRNE, J.; WOLCH, J. Nature, race, and parks: Past research and future directions for geographic research. Progress in Human Geography, v.33, n.6, p.743-765, 2009. http://dx.doi.org/10.1177/0309132509103156. 
CARRUS, G.; SCOPELLITI, M.; LAFORTEZZAC, R.; COLANGELOC, G.; FERRINI, F.; SALBITANOE, F.; AGRIMIF, M.G.; PORTOGHESIF, L.; SEMENZATOG, P.; SANESIC, G. Go greener, feel better? The positive effects of biodiversity on the well-being of individuals visiting urban and peri-urban green areas. Landscape and Urban Planning, v.134, p.221-228, 2015.

COMUNE, M. D; SURINANI-AFFONSO, A. L. Análise de três áreas verdes urbanas em Guarapuava, Paraná. Ambiência, Guarapuava, v. 10, n. 3, p. 723-739, 2014.

FERNANDES, C.J.; FERRAZ, M.V.; GIMENES, R.; PEREIRA, S.T.S.; PIVETTA, K.F.L. Trees description in the main square of São José do Rio Preto, São Paulo State, Brazil, Ornamental Horticulture, v. 24, n. 4, p. 334-340, 2018.

IBGE - Instituto Brasileiro de Geografia e Estatística. Disponível em: $<$ https://cidades.ibge.gov.br/brasil/sp/taquaritinga/panorama $>$.Acesso em: 09 de abril de 2020.

KRAMER, J. A.; KRUPEK, R. A. Caracterização florística e ecológica da urbanização praças públicas do município de Guarapuava-PR. Revista Árvore, Viçosa, MG, v. 36, n. 4, p. 647 $658,2012$.

LACERDA, R.M.A.; LIRA FILHO, J.A.; DOS SANTOS, R.V. Indicação de espécies de porte arbóreo para a arborização urbana no semi-árido paraibano. REVSBAU, Piracicaba - SP, v.6, n.1, p.51-68, 2011.

LORENZI, H. Plantas para jardim no Brasil: herbáceas, arbustivas e trepadeiras. Nova Odessa: Instituto Plantarum, 2013. p. 1-1118.

LORENZI, H.; SOUZA, H.M.de; TORRES, M.A.V.; BACHER, L.B. Árvores exóticas no Brasil: madeiras, ornamentais e aromáticas. 1. ed. Nova Odessa: Platarum, 2003. 368 p.

LORENZI, H.; SOUZA, H. M. Plantas ornamentais no Brasil: arbustivas, herbáceas e trepadeiras. 4.ed. Nova Odessa: Plantarum, 2008. 1088 p.

LORENZI, H.; BACHER, L.B.; TORRES, M.A.V. Árvores e arvoretas exóticas no Brasil: madeireiras, ornamentais e aromáticas. 4.ed. Nova Odessa: Plantarum, 2018. 464p.

MOREIRA, G.L.; LIMA, M.C.D. de; ROCHA, N.B.; CUNHA, D.V.P. da; FERRAZ, F.T. Diagnóstico quali-quantitativo da arborização de praças públicas na cidade de Planalto, BA. Agropecuária Científica no Semiárido, v.14, n.2, p.168-174, 2018.

OLIVEIRA, C.H.; SANTOS, J.E.; PIRES, J.S.R. Indicadores de arborização urbana da cidade de São Carlos (SP) com uso do SIG-IDRISI. Brazilian Journal of Ecology, v.3, n.1, p.1-9. 1999. 


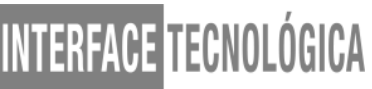

OLIVEIRA, A. S.; SANCHES, L.; MUSIS, C. R.; NOGUEIRA, M. C. D. J. A. Benefícios da arborização em praças urbanas-o caso de Cuiabá/MT. Revista Eletrônica em Gestão, Educação e Tecnologia Ambiental, v. 9, n. 9, p. 1900-1915, 2013.

ONU - Organização das Nações Unidas. Disponível em: < https://nacoesunidas.org>. Acesso em 15 julho de 2020 .

NUCCI, J.C. Qualidade ambiental e adensamento urbano: um estudo de ecologia e planejamento da paisagem aplicado ao Distrito de Santa Cecília (MSP). São Paulo: USP, FFLCH, 236p., 2001.

PIVETTA, K.F.L., PAIVA, P.D.O., NERI, F.C.S. Paisagismo em grandes espaços. In: PAIVA, P.D.O. Paisagismo; conceitos e aplicações. Lavras: UFLA, p.179-211, 2008. 457

ROMANI, G.de N.; GIMENES, R.; SILVA, M.T.; PIVETTA, K.F.L.; BATISTA, G.S. Análise quali-quantitativa da arborização na Praça XV de Novembro em Ribeirão Preto - SP, Brasil. Revista Árvore, v.36, n.3, p.479-487, 2012.

RIGOLON, A. A complex landscape of inequity in access to urban parks: A literature review. Landscape and Urban Planning, v.153, p. 160-169, 2016.

ROCHA, R. T. da; LELES, P. S. S. dos; OLIVEIRA NETO, S. N. de. Arborização de vias públicas em Nova Iguaçu, RJ: o caso dos bairros Rancho Novo e Centro. Revista Árvore, Viçosa, v. 28, n. 4, p. 599-607, 2004.

SILVA, C. D. D.; ALMEIDA, L. M. Composição florística e fitossociológica das praças do bairro de Neópolis, Natal-RN. Revista Cultural e Científica do UNIFACEX, Capim Macio, v. 14, n. 2, p. 86-103, 2016.

VAN DEN BERG, A.E.; MAAS, J.; VERHEIJ, R.A.; GROENEWEGEN, P.P. Green space as a buffer between stressful life events and health. Social Science \& Medicine, v. 70, p. 1203$1210,2010$.

VAN DEN BERG, M.; VAN POPPEL, M.; VAN KAMP, I.; ANDRUSAITYTE, S.; BALSEVICIENE, B.; CIRACH, M.; SMITH, G.; TRIGUERO-MAS, M.; UZDANAVICIUTE, I; WIT, P.; MECHELEN, W.;GIDLOW, C.; NIEUWENHUIJSEN , M.J.; KRUIZE, H.; MAAS, J. Visiting green space is associated with mental health and vitality: A cross-sectional study in four European cities. Health \& Place, v.38, p.8-15, 2016.

VIEZZER, J.; BIONDI, D.; MARTINI, A.; GRISE, M.M. A Vegetação no paisagismo das praças de Curitiba-PR. Ciência Florestal, v. 28, n. 1, p. 369-383, 2018. 